\title{
Manifesto do Coletivo do NESEF e Organizações Civis em Defesa da Gestão Democrática da Política Educacional
}

Curitiba, 12 de dezembro de 2014.

O NESEF, entidade de pesquisa educacional sobre a Educação Filosófica e o Ensino de Filosofia, atuante há mais de duas décadas na defesa de uma educação de qualidade, norteada pelo ideal da formação integral dos sujeitos e extensiva a todos os cidadãos brasileiros, em conjunto com entidades associadas, dirige-se, de modo geral, à Sociedade Paranaense e Brasileira e, de modo particular, às Instituições Públicas e Entidades Civis relacionadas ao final desta Carta-Manifesto, a fim de demarcar seu posicionamento quanto às diretivas que vem norteando as políticas educacionais em curso no Estado do Paraná e no Brasil.

As referidas diretivas têm em comum o fato de ora francamente aviltarem, ora desrespeitarem os princípios básicos, constitucionalmente determinados, da gestão democrática de todas as instâncias educacionais. Entendemos que a democracia num Estado Republicano como o nosso não pode ser entendida e praticada pelas administrações públicas como um mero epifenômeno, somente válido discursivamente nos períodos eleitorais. Com efeito, a democracia, como valor e como prática, vem arrefecendo no âmbito da política nacional de educação, justificada pela necessidade de amplas alianças que garantiriam a governança necessária. Já, no Paraná, o horizonte apresenta-se grave e inóspito aos direitos sociais educacionais mais básicos. Por aqui, os valores e práticas democráticas, de forma mais flagrante, foram completamente esquecidos, tão logo o poder discricionário dos "eleitos" se configurou "autoridade" legalmente constituída.

É contra as recentes investidas governamentais aos direitos de todos os cidadãos à educação básica pública e contra a gestão centralizada e autoritária - tanto do locus da proposição, quanto da implementação - das políticas públicas socioeducacionais que se posiciona este Manifesto.

Aos leitores deste texto, sobretudo os líderes governamentais, pode parecerlhes utópico ou mesmo impertinente que um grupo de professores de filosofia, sociologia, história, geografia, pedagogos, de advogados que atuam no campo popular, 
lideranças de movimentos sociais, da oposição parlamentar e dos comunicadores midiáticos alternativos, se levantem contra uma engrenagem poderosa e "legalmente" eleita. A esses, informamos que a democracia não se traduz pelo pseudoparticipacionismo e muito menos é um valor quantitativo. Ao contrário, entendemos que mecanismos de sedução da subjetividade e arregimentação verticalizada de "apoios" como o fenômeno do "bolsismo curricular" federal e das benesses aos Diretores de Escola paranaenses, dos quais trataremos adiante - e argumentos relativamente à "autoridade máxima" executiva que, uma vez conquistada nas urnas, concede o direito ao gestor de fazer o que bem lhe aprouver, em nome dos "representados", constituem-se em atos mais próximos aos valores autocráticos do que democráticos. Esse modelo de prática política, no nosso entendimento, precisa ser redimensionado, uma vez que a democracia se baseia justamente no diálogo horizontal e, acima de tudo, qualificado.

Triste é que cidadãos, organizados ou não, em grupos de resistência como este ou mesmo, individualmente, numa república, em tese, democrática como a nossa, tenham que se valer de justificações perante as "autoridades" do poder público para que se façam, por elas, ouvir e que se estabeleça, com elas, o diálogo. Porém, muito peculiar e contraditoriamente na conjuntura que nos encontramos, os Manifestos fazem-se necessários.

Entendemos que a reeleição da Presidenta Dilma só foi viabilizada mediante a militância de grupos como o nosso, que, ante a possibilidade do retrocesso, optou e posicionou-se publicamente pelo projeto que prometia o aprofundamento das mudanças estruturais. Nos posicionamos criticamente sobretudo em relação às promessas do atual governador reeleito no Paraná. Seus $55 \%$ de eleitores foram mobilizados pela possibilidade de melhora global de suas vidas, incluindo-se aí, os serviços sociais (saúde, segurança, transporte, educação) e as pautas econômicas (emprego, renda e medidas que protejam o trabalho). Assim, imbuídos pelo direito cidadão, vimos nos manifestar em relação aos pontos que seguem e para os quais esperamos, em nome da Constituição Federal e da Democracia Republicana, respostas do poder público.

I. Com relação à política curricular nacional, exigimos que o nosso legítimo direito de participar das discussões seja atendido, pois entendemos que está em curso uma proposição que caminha para a dissolução das disciplinas (sobretudo as Humanidades) e para os modelos flexíveis, destituídos de identidade epistemológica. 
Os principais termômetros dessa viragem - além do PL 6840/2013, este que já foi objeto de Manifesto específico do NESEF, e o recentemente projeto apensado, o PL 7.058/2014, que concretiza o projeto de qualidade formadora mínima e qualidade mercantil máxima da escola básica pública - são o Pacto Nacional pelo Fortalecimento do Ensino Médio e o recente projeto de discussão do Currículo Nacional Unificado.

Quanto a esse último, embora as discussões pretensamente "democráticas" tenham se iniciado tão somente no âmbito das IES (Instituições de Ensino Superior) e das Secretarias de Educação, esperamos que, conforme anunciado no website da Secretaria de Educação Básica do MEC, a ampliação do debate comtemple representantes da própria Educação Básica em atuação nas escolas deste país.

Com relação ao Pacto Nacional pelo Fortalecimento do Ensino Médio, nos chama atenção o fato das IES Públicas terem abdicado do seu papel de críticas às políticas educacionais tornando-se, em conjunto com as Secretarias de Estado da Educação, implementadoras dessas políticas, chancelando-as ao invés de discuti-las. Ora, pode-se argumentar que a "adesão" massiva ao Pacto Nacional pelo Fortalecimento do Ensino Médio se deu em razão da concordância com os seus termos. Este argumento, no entanto, cai por terra, pois os Cadernos foram publicizados após a "adesão" ao mesmo, logo, a "adesão" massiva tem outra explicação. Trata-se, a nosso ver, do fenômeno que temos chamado de "bolsismo curricular". A farta distribuição de bolsas, sem critérios transparentes, a coordenadores, multiplicadores, orientadores e cursistas, acrescidas de verbas para publicações de livros e organização de eventos, novamente a nosso ver, é o principal fator que explica a adesão. Não somos, em princípio, contra o financiamento público para a formação continuada dos professores, ao contrário, defendemos e lutamos para que a formação presencial com qualidade pedagógica e epistemológica ocorra e se amplie. Somos críticos em relação a uma iniciativa que se apresenta como "Formação", mas que traz uma proposta de "Reforma Curricular" embutida nos seus propósitos contando para tanto, conforme dissemos, com a farta distribuição de bolsas a pessoas que, em sua maioria, ao menos no âmbito estadual, não apresenta nenhum histórico e comprometimento intelectual e pedagógico para analisar o currículo, pois seu mérito é tão somente o enquadramento no jogo de interesses da política local. Enquanto os coordenadores estaduais e orientadores de estudos do Pacto Nacional pelo Fortalecimento do Ensino Médio forem escolhidos sem critérios discutidos e corroborados democraticamente pelos trabalhadores da educação, 
o que se pode esperar? Nesse sentido, alertamos aos cursistas do Pacto do Ensino Médio que, além dos $\mathrm{R} \$ 200,00$ mensais e das horas de formação válidas para suas progressões na carreira, está em jogo o futuro da organização curricular disciplinar e, com isso, o futuro de suas próprias especialidades. O currículo flexível organizado por Áreas de Estudo e Projetos resolve, tal como se vem afirmando no Paraná, o déficit de profissionais formados em campos e disciplinas específicos. Atualmente a imensa maioria dos professores é licenciada em cursos específicos, isto é, ainda não organizados em Áreas. Nessa lógica, a rigor, lecionam disciplinas para as quais têm formação. Porém, devido à desvalorização da carreira do magistério vem sendo constatado déficits de professores para várias disciplinas, o que é um problema para as administrações públicas. Diferente seria o panorama, suspiram esses governantes, se o currículo fosse mais flexível, mais transverso e livre dos rigores do conhecimento. $\mathrm{O}$ problema da especialidade docente simplesmente desapareceria, pois, na prática, com exceção da Matemática (que pelas novas Diretrizes Curriculares Nacionais, é ao mesmo tempo, área e disciplina) todos poderiam "dar aula" de todos os conteúdos pertencentes à sua área de formação. Perguntamos: é essa a qualidade educacional que almejamos? Com base nessas considerações, exigimos que o MEC e a SEED PR se posicionem em relação:

1. aos conteúdos do Pacto Nacional pelo Fortalecimento do Ensino Médio, no que diz respeito aos critérios de indicação de seus proponentes e relatores; aos financiamentos liberados para tais produções; aos conceitos utilizados nos cadernos, muitos deles discutíveis do ponto de vista de correção conceitual e rigor filosófico;

2. à indicação e acompanhamento dos coordenadores e demais envolvidos nos âmbitos estaduais (indicados pelas Secretarias de Educação, segundo critérios desconhecidos pela totalidade das Redes) e orientadores dos grupos nas escolas (indicados pelos diretores de escola). Nesse cenário, não é de estranhar que grande parte dos profissionais paranaenses que estão conduzindo esta reforma não tenham sequer um conhecimento geral mínimo sobre currículo.

3. os reais objetivos do Pacto Nacional pelo Fortalecimento do Ensino Médio, pois entendemos que o que se chama popularmente de "agir pela beiradas" é a estratégia nesse caso. Oferece-se um curso aos professores e, nele, embute- 
se uma nova realidade curricular. Lembramos que os profissionais, a princípio, aderiram à participação em um curso e não ao projeto de dissolução de suas próprias especialidades profissionais. Mais cedo ou mais tarde, as intenções terão de ser objetivadas.

\section{Com relação à política curricular e pedagógica estadual, exigimos que} as mudanças já em curso, em pleno período de transição governamental, não sigam, tal como estão postas, em medidas isoladas e autocráticas, sem a discussão ampla no âmbito da Rede Estadual de Educação. A primeira medida educacional do Governo recém-reeleito, ainda antes da "nova posse", foi, partindo de uma benesse concedida a diretores de escola e da maioria legislativa que sua base de apoio tem na ALEP (Assembleia Legislativa do Paraná), anular o direito à consulta à comunidade escolar para escolha de diretores das escolas estaduais. Com base no argumento meritocrático, mas que em realidade traduz-se em "troca de favores" políticos a parcelas de diretores atuais, de quem se espera apoio para as medidas educacionais, o Governo consolidou seu intento e, dessa forma, uma construção, resultante de luta histórica dos profissionais da educação do Paraná, foi desmontada celeremente.

$\mathrm{Na}$ sequência das medidas, já com o apoio de vários diretores aliados ao Governo em troca de um, ou mais alguns, anos de "poder" e "gratificações", anunciouse o fechamento de centenas de escolas, a maioria do Campo e de Educação de Jovens e Adultos, cuja relação custo-benefício não atende à economicidade da lógica do Governo. Sob os protestos da sociedade paranaense, a tática mudou, mantendo-se a lógica que a sustenta: ao invés de fechar centenas de escolas, optou-se por fechar apenas uma dezena de escolas e centenas de turmas em várias escolas de todo o Estado.

Como se não bastassem as medidas saneadoras, em nome dos "baixos resultados" dos estudantes nos Exames do Sistema de Avaliação da Educação Básica SAEB (expresso pelo IDEB - Índice da Educação Básica) e, no estadual, Sistema de Avaliação do Estado do Paraná - SAEP ( cujos resultados nunca foram publicizados amplamente, embora o custo do sistema seja enorme), sobreveio a medida relacionada à eficiência do Sistema Educacional, traduzida na proposta de "correção do fluxo" escolar, justificada pela distorção idade/série-ano entre os matriculados nas escolas da Rede. Distorção entendida pelo Governo como uma deformação resultante, não da ausência de elementos básicos como formação continuada aos profissionais, infraestrutura escolar e condições de trabalho pedagógico docente e discente, mas de 
questões outras, como falta de empenho das escolas e de seus profissionais. Ante a tais medidas, e outras que se prenunciam, pois já foram objeto de iniciativas não concluídas em anos anteriores, tais como: (a) a alteração do formato presencial do Programa de Desenvolvimento Educacional - PDE Estadual; (b) o fechamento de cursos da Educação Profissional e (c) a unificação da Matriz Curricular do ensino médio, com parte da carga horária a distância, exigimos que a Secretaria de Estado da Educação do Paraná se posicione com respeito aos seguintes itens:

1. como ficam os direitos educacionais dos estudantes sem escolas? E dos professores concursados sem trabalho? Serão simplesmente remanejados para escolas "próximas"? (sabemos que há casos em que o termo "próximo" significa “município próximo"). Como é possível que um governo eleito simplesmente tire o direito à educação de cidadãos com base num critério quantitativo? Quer dizer que, se em dada localidade ou escola, os atendidos são poucos (ou seja, as turmas não chegam a 40 ou 45 alunos), esses poucos devem ser alijados de seus direitos?

2. os profissionais da educação não são apenas implementadores de políticas. Aliás, quaisquer medidas autocráticas tendem a fracassar, pois dificilmente contarão com os apoios necessários à sua consolidação. Assim, a correção de fluxo, colocada em muitas escolas como uma "adesão obrigatória", enquanto instrumento de adequação da idade ao ano/série, deve ser discutida pela Rede antes de implementada, pois mesmo se os gestores desavisadamente pensam em "lucrar" apenas nos números das avaliações, nós os informamos, que nesse caso, o "lucro" se auto-anula. Ganha-se no quesito distorção mas perde-se no quesito proficiência, pois a aprovação (ou o fato de SIC! "pular” duas séries, como os defensores do Programa têm anunciado em suas falas "pedagógicas"), não garante, obviamente, a aprendizagem;

3. o acesso aos resultados do SAEP é um direito dos educadores e da sociedade. Já que este tem sido usado para sustentar dezenas de medidas e é custeado pelo fundo público, pergunta-se porque os resultados não são públicos? Uma vez que, ao que nos parece, a fragilidade da qualidade educacional fica evidenciada neste Exame, estaria aí o motivo de sua não divulgação?

Finalizando este item, reiteramos que é dever do Estado respeitar às construções históricas dos trabalhadores em educação, as quais, embora sejam objetos de leis 
específicas, vêm sendo tratadas de forma ora autoritária, ora baseada numa falsa meritocracia, abstraindo-se delas suas dimensões pedagógicas e políticas, prevalecendo as justificações administrativas. Nós, os sujeitos da educação pública não somos meros empregados ineptos de uma "empresa educacional" que carece de um ordenamento administrativo para que seus "produtos" tenham a qualidade esperada pelo mercado educacional brasileiro. $\mathrm{O}$ respeito aos trabalhadores da educação e seu papel formador deveria ser ponto de honra para qualquer Governo que afirme a educação como prioridade.

\section{Com relação às constantes e recentes investidas contra o direito à} educação pública dos jovens, adultos e idosos que acorrem à Modalidade da Educação de Jovens e Adultos (EJA) no Paraná, exigimos tão somente que se respeite tal direito. Essa pauta, já foi objeto de manifestação deste Coletivo e, pelas razões já comentadas no início do presente texto, não nos causou surpresa o fato de sermos ignorados pelo Governo do Paraná, que tem se eximido de dar explicações à sociedade, que, pela atitude displicente, parece considerá-la algo menor no horizonte de seus próprios interesses. Esperamos estar errados a este respeito e, desta vez, obtermos as respostas às nossas perguntas. No Paraná, entre outras atitudes de franco desrespeito ao direito subjetivo à educação, a nova organização da EJA, expressa em normativas estaduais traduz-se em retrocesso em relação à política educacional, que a duras penas, os educadores, os estudantes e demais cidadãos organizados desse Estado vêm conseguindo concretizar.

Segundo os Fóruns Paranaense e Nacional de EJA, os dados censitários de 2010, demonstram que, no Paraná, são mais 5 milhões de pessoas com 15 anos ou mais sem a Educação Básica completa. Destes, “3,5 milhões estão sem instrução e sequer concluíram o ensino fundamental". Logo, o Estado não pode afirmar que não há demanda para a EJA e, é seu dever, em colaboração com a sociedade, conforme preceito constitucional, garantir as condições para que o direito educacional desses mais de 5 milhões de paranaenses possa ser exercido.

Em lugar de "política de formação", no Paraná, a EJA, sob a liderança do atual Departamento de Educação de Jovens e Adultos (DEJA), em parceria com instituições privadas e com o apoio, ao menos parcial, do Conselho Estadual de Educação (CEE PR), vem transformando a EJA em "política de exames" online. Assim, o incentivo para 
que a iniciativa privada ofereça "cursos rápidos" ao público da EJA é visível. Eles proliferam em todo o Estado, a preços módicos e qualidade igualmente módica. Ao Estado só caberia instalar a estrutura de exames e certificação em massa e construir os bancos de itens para as constantes ofertas de avaliação online. É para isso, ou seja, para consolidar um negócio lucrativo para as empresas e destituído de possibilidades de formação integral dos estudantes que nós, sociedade paranaense, mantemos, com nossos impostos, toda uma equipe alocada na Secretaria de Estado da Educação? Não seria o público da EJA, também ele, sujeito de direitos educacionais qualitativamente superiores, considerando-se que a simples existência da EJA já representa o não cumprimento pelo estado dos direitos básicos dessa parcela da população?

Com base nesses considerandos, exigimos que a SEED/PR se manifeste sobre os seguintes itens:

1. para planejar, gerir e executar a política educacional espera-se que sejam indicadas pessoas que possuam conhecimentos acumulados para este exercício, além de sensibilidade social e respeito às lutas, debates e produções no campo da educação. Um projeto educacional não se esgota nele mesmo: é preciso que os dirigentes governamentais entendam que a Educação, sobretudo a Pública, é eminentemente social. A nova organização da EJA não expressa valores humanos ou sociais, sendo implícitas suas finalidades economicistas e tecnocráticas.

2. a solução "administrativa", para a economia de recursos investidos na Modalidade, prevalece em detrimento das necessidades pedagógicas dos estudantes e professores. Ou seja, seus autores e defensores, ao buscar maior eficácia e eficiência e, com isso, diminuir os "gastos" com educação, contribuem para que a dívida social com todos os que não tiveram oportunidades educacionais aumente e se consolide. Nesse sentido, indaga-se se é de fato o entendimento da SEED/PR que uma política de exames satisfaz plenamente o problema administrativo, relegando-se a dimensão pedagógica da EJA a uma quase nulidade.

Por fim, em nome da Educação Pública, Gratuita, Universal, Laica e de qualidade o NESEF e entidades associadas, mais uma vez, solicita aos dirigentes da União, Ministério da Educação (MEC) e Secretaria de Estado da Educação (SEED/PR) que, respeitando-se o caráter republicano e as prerrogativas do Estado Democrático de 
Direito, doravante, na proposição de políticas públicas educacionais, considerem, além de questões administrativas e da vontade política específica do grupo que exerce o poder, as necessidades, os interesses e as peculiaridades de estudantes, professores e comunidades escolares.

Nós do NESEF/UFPR e entidades associadas (enumeradas ao final deste Manifesto), assim como de dezenas de outras entidades organizadas da Sociedade Civil preocupadas com a política educacional, estamos dispostos a exercer o papel de partícipes em todas as iniciativas que realmente contribuam para os avanços educacionais que a sociedade brasileira exige e aos quais têm direito. Porém, para tanto, é preciso que os governantes sejam educados para nos verem não somente como eleitores, mas como cidadãos e sujeitos de direitos a quem a democracia deveria dar voz.

Este Manifesto foi apresentado à sociedade, aprovado no Mérito e Redação ao longo dos trabalhos do XVI Encontro do Coletivo do NESEF e do II Seminário de Políticas Públicas e Educação Filosófica e segue para avaliação e considerações dos seguintes órgãos, entidades e pessoas:

Ilma. Presidenta da República, Sra. Dilma Rousseff

Secretaria Federal de Articulação Política - Ilmo. Sr. Gilberto de Carvalho

Ilmo. Governador do Paraná, Sr. Carlos Alberto Richa

Ministério da Educação - Secretaria de Educação Básica

Secretaria de Estado da Educação do Paraná - Gabinete e Superintendência

Ministério Público Federal - Centro de Apoio Operacional às Promotorias de Justiça da Criança e do Adolescente e da Educação - CAOPEduc

Fórum Nacional de EJA

Fórum Paranaense de EJA

APP-Sindicato - Sr. Hermes Leão

Representação da UNESCO no Brasil - Organização das Nações Unidas. Brasília- DF. 
Comissão de Educação da Assembleia Legislativa do Paraná

Conselho Nacional de Educação

Conselho Estadual de Educação

Membros do Fórum Estadual de Educação do Paraná

Membros do Conselho do Setor de Educação da UFPR

Departamento de Teoria e Prática de Ensino (DTPEN/UFPR) 